\title{
EL RELATO DE VIAJE EN LA PRENSA DE LA ILUSTRACIÓN: ENTRE EL PRODESSE ET DELECTARE Y LA INSTRUMENTALIZACIÓN SATÍRICA
}

\author{
Francisco UZCANGA MEINECKE \\ Universidad de Ulm (Alemania)
}

\section{RESUMEN}

El artículo se plantea analizar la importancia del relato de viaje en la prensa de la segunda mitad del siglo XVIII, más concretamente de la década de los ochenta, su época de mayor apogeo. Una primera parte se ocupa de los relatos de viaje reales que incluye la prensa con la intención principal, en el marco del prodesse et delectare tan propio de la Ilustración, de instruir de forma amena a sus lectores sobre el 'carácter y las costumbres de las naciones extranjeras'. A continuación se estudian aquellos relatos de viajes imaginados o ficticios cuya principal función es servir de soporte para realizar a través de ellos una crítica social y política.

Palabras clave: relato de viaje, prensa, Ilustración.

\section{THE TRAVELOGUE ON THE PRESS OF THE ENLIGHTENMENT: BETWEEN PRODESSE ET DELECTARE AND SATIRIC INSTRUMENTAL USE}

\begin{abstract}
The article pretends to analyse the importance of travelogue in the press of the second half of the 18th century, especially the eighties, its high period. A first section deals with real travelogues included in the press, in line with the characteristic enlightened concept prodesse et delectare, which means instructing the readership in an amusing way about 'foreign character and customs'. In a second section there is a study about fictitious and imaginary travelogues whose main function is to become a medium for political and social critic.
\end{abstract}

Key Words: Travelogue, Press, Enlightenment.

El sábado 10 de octubre de 1795 el Diario de Madrid publica la carta de un corresponsal partidario de que los jóvenes viajen al extranjero. Afirma el corresponsal que es la juventud la mejor edad para viajar y aduce que un viaje emprendido antes de la madurez no sólo redunda en beneficio propio sino también en provecho de la patria; aunque eso sí, concede, ha de tratarse de un joven de buena crianza, sólida religión e instruido en los rudi- 
mentos de la lógica y la filosofía. Dos semanas después, el domingo 25 de octubre, envía el corresponsal otra misiva con la intención de reforzar su postura y añadir un aspecto nuevo y relevante: antes de emprender el viaje, escribe, el joven ha de haber leído una buena porción de libros de los más célebres viajeros para estudiar en ellos el modo en que debe viajar. Porque, «al que ha de edificar palacios y casas, ¿no le enseñan antes la aritmética, la geometría y la arquitectura? Al que ha de tomar el pulso y recetar purgas y sangrías, ¿no le hacen estudiar antes los libros de Hipócrates y Galeno? Pues, ¿por qué se ha de poner a viajar a un joven sin instruirle anticipadamente en los libros que han escrito los juiciosos viajeros?».

El problema, admite el corresponsal, es que resulta difícil encontrar este tipo de libros «en nuestra lengua». Cita como solitario ejemplar el viaje de Antonio Ponz ${ }^{1}$, lo descarta por ser su lectura más apta para el «estudio de las bellas artes que para hacer comparación y estudio del carácter y costumbre de las naciones», y se congratula de la reciente aparición de una colección titulada Viajero universal que reúne una serie de relatos de viaje que «van escritos con un método tan atractivo que parece cada tratado una novela según deleita». Una obra, asegura el corresponsal al final de su carta, que va a suplir la carencia de libros de viaje en lengua española.

El título completo de la colección a la que se refiere el corresponsal es Viajero universal o noticia del mundo antiguo y nuevo, obra recopilada de los mejores viajeros. Su autor, el presbítero Pedro Estala, se había propuesto en un principio traducir la obra del jesuita francés Joseph La Porte Le voyageur françois ou la connoissance de l'ancien et du nouveau monde, aunque pronto, a partir del tomo quinto, decide liberarse del original francés, reorganizar los viajes por ámbitos geográficos, incluir reflexiones y comentarios propios, y, sobre todo, incorporar relatos de viaje más recientes, en especial los que refieren los últimos descubrimientos. La obra fue editada entre 1795 y 1801, llegó a alcanzar 43 volúmenes y se acabó convirtiendo en una de las empresas editoriales más exitosas de finales de siglo.

Tuvo sin duda Estala olfato editorial, y, como vaticinaba el corresponsal del Diario de Madrid, su versión metódica y actualizada del Voyageur supo llenar un hueco del mercado editorial, ya que los lectores españoles interesados en las últimas novedades de literatura de viajes en estos años finales del siglo XVIII se encontraban con una oferta de libros muy escasa. Las causas de esta escasez pueden buscarse en la falta de hábito viajero de los españoles, en el carácter privado u oficial de no pocos textos — cartas, diarios, informes - en los que se relatan viajes, en la lentitud y las trabas administrativas para la concesión de permisos de edición, en la permanente

\footnotetext{
${ }^{1}$ Se refiere al Viaje fuera de España (1785) del teólogo e historiador del arte Antonio Ponz y que transcurre por los Países Bajos, Francia e Inglaterra.
} 
amenaza de la censura, tanto civil como eclesiástica... Lo cierto es que la mayor parte de los viajes que conocemos de la época de la Ilustración - escritos por Jovellanos, Leandro Fernández de Moratín, Viera y Clavijo, Tomás de Iriarte, Sarmiento, Campomanes...- no serían publicados hasta muchos años después ${ }^{2}$. Y también los libros de los principales viajeros extranjeros de aquellos años tuvieron que esperar varias décadas para ser traducidos ${ }^{3}$.

Unos años atrás, antes de que el ministro Floridablanca, alarmado por las noticias que llegaban de la Francia revolucionaria, estableciera cordones sanitarios y restringiera la libertad de prensa, la situación era algo distinta. Aunque el mercado de libros de viaje se mantenía igualmente yermo, los lectores interesados en las últimas novedades de literatura de viajes podían recurrir a la variada y generosa gama de relatos de viaje que le ofrecían las publicaciones periódicas. Esto es algo que no debe sorprender a priori, si atendemos a la importancia que alcanza la prensa como instrumento cultural y a la trascendencia del viaje como fenómeno sociológico y literario durante la segunda mitad del siglo XVIII.

A partir de los años sesenta surgen en España una serie de publicaciones periódicas que, junto al afán de informar a la opinión pública, tratan también de divulgar a través de sus páginas la corriente cultural e ideológica que llamamos Ilustración. De talante progresista y reformador, la mayoría de los pioneros editores, o si se quiere protoperiodistas -Francisco Mariano Nipho, José Clavijo y Fajardo, más tarde José María García del Cañuelo- y sus múltiples colaboradores —entre ellos Jovellanos, Meléndez Valdés o Tomás de Iriarte- se sirven de este novedoso medio para impulsar en España el nuevo espíritu que va ganando terreno en toda Euro$\mathrm{pa}^{4}$. En busca de novedades literarias, modas y tendencias, temas de actualidad política y social que dar a conocer a sus lectores, los periodistas vuelven sus ojos a los países que están a la vanguardia de la Ilustración, en especial Inglaterra y Francia. Y en la Europa más ilustrada se vive durante esta segunda mitad del siglo XVIII una verdadera fiebre viajera. Es la época en la que culmina el conocimiento geográfico de la tierra, gracias a los descubrimientos de James Cook por los mares del sur y las

${ }^{2}$ Véase ÁLVAREZ MIRANDA, Pedro. «Los libros de viajes y las utopías en el siglo XVIII español». En: CARNERO, Guillermo (coord.). Historia de la literatura española 7. Siglo XVIII (II). Madrid: Espasa Calpe, 1995, p. 688.

${ }^{3}$ El caso más significativo es el de James Cook: hasta 1832 no se editó el primer libro en español de sus viajes. Véase TORRES SANTO DOMINGO, Marta. «Los viajes del capitán Cook en el siglo XVIII. Una revisión bibliográfica». Biblio 3W, Revista bibliográfica de geografía y ciencias sociales, 2003, VIII, núm. 441, p. 1.

${ }^{4}$ Para una panorámica de la prensa española de la Ilustración puede consultarse el capítulo de Inmaculada Urzainqui: «Un nuevo instrumento cultural: la prensa periódica». En: ÁLVAREZ BARRIENTOS, Joaquín; François LOPEZ e Inmaculada URZAINQUI. La república de las letras en la España del siglo XVIII. Madrid: CSIC, 1995, pp.125-216. 
exploraciones al África Central. Son años también en los que se desarrollan invenciones que posibilitan una nueva movilidad, como el globo aerostático de Montgolfier, que inicia el viaje aéreo. La prosperidad económica hace además que se mejoren los caminos, las calzadas, que se modernicen los medios de transporte. Es también la época del apogeo del Gran Tour, el viaje educativo para los jóvenes de buena familia, una costumbre británica en su origen pero que pronto se extiende entre buena parte de la aristocracia y la -incipiente- burguesía europeas. La fiebre viajera encuentra asimismo eco en el ámbito intelectual, con la reactivación de la disputa sobre la utilidad de viajar, una discusión ya clásica - recordemos, por ejemplo, la carta de Séneca a Lucilo (Epistolae morales 28) o la carta de Horacio a Bullatius (Epistolae I, 11)—, que fue abordada después por pensadores de la talla de Montaigne, Bacon, Locke 5 , y que recibe un nuevo impulso en este siglo, tan obsesionado por la utilidad social y la función educativa, gracias sobre todo a la aportación de Rousseau en su célebre capítulo del Emilio dedicado a los viajes. Finalmente, el fenómeno del viaje se refleja también en el mercado editorial: se reeditan numerosos viajes antiguos, se publican voluminosas colecciones de viajes $\mathrm{y}$, sobre todo, sale a la luz una ingente cantidad de libros de viajeros contemporáneos, todo ello para aplacar la creciente demanda de un público ávido de este tipo de literatura ${ }^{6}$. No cabe duda de que estamos en esta segunda mitad del siglo, la plenitud de la Ilustración, no sólo en una de las época más viajeras, sino también en uno de los periodos de auge de la literatura de viajes en Europa; incluso se puede afirmar que es también la época en la que se crea el género del relato de viaje tal como actualmente lo entendemos.

Basta un somero repaso a la prensa de la segunda mitad del siglo XVIII, en especial a la de la década de los ochenta ${ }^{7}$, para percibir hasta qué punto el fenómeno del viaje encuentra resonancia en España. Es cierto que el hábito de viajar no está aquí tan extendido, y es cierto también que, en comparación con Inglaterra o Francia, apenas se publican libros de viaje; pero, al igual que la prensa de otros países europeos, los periódicos españoles informan profusamente sobre los últimos descubrimientos, reseñan las

\footnotetext{
${ }^{5}$ Michel de Montaigne: Essays I, 25; Francis Bacon Essays, 18; John Locke, Some thoughts concerning education, 212-216.

${ }^{6}$ En su bibliografía de libros de viajes de 1808, Boucher de la Richarderie contabiliza un total de 3540 relatos de viajes publicados en este siglo en Europa, lo que supone el doble que en el siglo anterior y siete veces más que en el siglo XVI. Citado por ROCHE, Daniel. «Viajes». En: FERRONE, Vicenzo y Daniel Roche (eds.). Diccionario histórico de la Ilustración. Madrid: Alianza Editorial, 1998, p. 293.

${ }^{7}$ Después de una época de declive debido a las medidas cautelares y represoras tras el motín de Esquilache, en 1766, la prensa volvió a surgir con fuerza en la década de los ochenta, al amparo de una serie de leyes promulgadas por el gobierno de Floridablanca. Es la llamada década dorada de la prensa dieciochesca, que duró hasta la Real Orden del 24 de febrero de 1791 que prohíbe la mayor parte de las publicaciones periódicas.
} 
novedades del género, ofrecen a sus lectores multitud de métodos y planes para viajar con utilidad ${ }^{8}$, y, lo que más nos interesa a nosotros, publican en sus páginas numerosos relatos de viaje. La única diferencia es que la labor de la prensa en España no es tanto complementaria o competidora de la industria del libro cuanto sustitutoria: hasta la publicación de la colección de Estala se puede decir que la prensa se erige en la principal — casi única - traductora y editora de relatos de viaje.

Aunque encontramos ya relatos de viaje en publicaciones tempranas ${ }^{9}$, es a partir de la década de los ochenta, los años de apogeo de la prensa, cuando observamos prácticamente en todos los periódicos, tanto de carácter informativo, cultural como crítico, una reiterada presencia de relatos de viaje. Si bien hallamos también relaciones de viaje históricas, predominan, como es propio de un medio que busca la actualidad inmediata, aquellos relatos contemporáneos y que informan de los descubrimientos más recientes. Unas muestras: el Mercurio de España incluye en sus números de febrero y julio de 1784 dos largas relaciones de Pilatre de Rozier, quien se había embarcado poco antes en un globo aerostático pilotado por Montgolfier; en el número de marzo de ese año el mismo periódico publica un extracto del viaje del Coronel Cooper a la India, quien refiere las primeras escaramuzas del ejército colonial inglés en aquel país; en noviembre de 1786 se edita, también en el Mercurio, «la sustancia» del relato de la primera ascensión al Montblanc, llevada a cabo pocos meses antes por Jacques Balmat y Michel Paccard; como muestra del interés que sigue despertando América, el Memorial Literario regala a sus lectores en enero de 1787 el Diario de la expedición hecha a las montañas de Zamora, que relata la expedición del corregidor Manuel Vallano y Cuesta por esta región ecuatoriana con el objeto de «reconocer a los indios infieles»; el 23 de junio de 1788, el Diario de Madrid publica un resumen de las recién editadas memorias de viaje por el África Central — «tierras ocultas y algunas no pisadas de planta humana»- del naturalista holandés Vaillant; también el Espíritu de los mejores diarios publica entre diciembre de 1790 y enero de 1791 un extenso extracto del Viaje hecho para descubrir las fuentes del Nilo, de Santiago Bruce; el mismo Espíritu de los mejores dia-

${ }^{8}$ Ver aquí ÁLVAREZ MIRANDA, Pedro. «Los libros de viajes y las utopías en el siglo XVIII español». En: CARNERO, Guillermo (coord.). Historia de la literatura española 7. Siglo XVIII (II). Madrid, 1995, p. 685.

${ }^{9}$ Por ejemplo, en el Diario noticioso, curioso, erudito, comercial, público y económico, el cual en su edición del 19 de agosto de 1760 inicia una serie titulada «historia y colecciones de los viajes». Las palabras con las que anuncia la nueva serie son reveladoras de los motivos por los que se decide a publicar los relatos de viaje: «Creemos poco necesario manifestar de cuanta instrucción y gusto son estas noticias, particularmente en España, donde no es frecuente la ventajosa costumbre e inclinación de viajar, como lo practican las más naciones de la Europa, y por lo mismo estas relaciones son más apreciables porque suplen en parte lo que el genio, en general, de la nación, estorba que adquiramos personalmente». 
rios publica entre el 28 y el 31 de enero de 1788 un compendio del reciente Viaje de Enrique Swinburn, por España; y a partir del 14 de octubre de 1790 y hasta el 12 de diciembre de 1790 el Diario de Madrid publica en amplio extracto la relación del tercer viaje de James Cook, entre 1776 y 1779 , el cual «suministra un campo geográfico tan vasto y ameno de materias instructivas, como sembrado y fértil de noticias agradables», adelantándose así en más de cuarenta años a la primera edición en español de los viajes de Cook.

Los relatos se publican enteros, extractados o resumidos mediante paráfrasis. Unas veces van incluidos en secciones que llevan títulos como «costumbres extranjeras», «historia natural», «geografía moderna» o simplemente «viajes»; otras se insertan sin más en alguna página del diario ${ }^{10}$. Las formas que adoptan son varias: aunque predominan la carta, la relación y la descripción, encontramos también diarios, itinerarios, informes, memorias, observaciones o geografías. En los prólogos y comentarios que anteceden a la transcripción del relato casi nunca se cita la edición ni la fuente, aunque es muy probable que gran parte de los relatos —en una época sin derechos de autor - fueran sacados de periódicos extranjeros. En ocasiones tampoco se cita al viajero y autor del relato, y se habla simplemente de un «viajero» o de un «viajante». Habitual en la mayoría de las presentaciones es la preocupación por recalcar el crédito del autor del relato, la veracidad de lo escrito. Y común a todas ellas, casi sin excepción, es recurrir al tópico horaciano del prodesse et delectare, tan caro a la literatura de la época, y que anuncia la principal intención que se persigue con la publicación de los relatos de viaje: instruir de forma amena sobre el carácter y las costumbres de regiones y pueblos extranjeros.

El prodesse et delectare pregonado por los periodistas se enmarca dentro del utilitarismo propio de la Ilustración. Pero si atendemos al medio en que se publican estos relatos y al hecho de que en muchos de ellos la balanza se inclina del lado del delectare, se puede vislumbrar también una función más pragmática: la necesidad de vender periódicos. De ahí, por ejemplo, que no sea raro toparse con escenas que, más que mostrar el 'carácter y las costumbres de las naciones', se diría que tratan de impresionar al lector, escenas que parecen acercarse a lo que hoy conocemos como periodismo sensacionalista. A modo de ejemplo, sirva este pasaje del relato de viaje por el norte de África que incluye el Diario de Madrid en su número del 8 de enero de 1788, y en el que se describe una procesión de comedores de serpientes de la que es testigo el viajero:

\footnotetext{
${ }^{10}$ Como explica el Diario de Madrid, al anunciar los viajes de Cook en su número del 14 de octubre de 1790: «de este literario manantial utile dulci, iremos sacando y traduciendo algunas cosas para este periódico, insertándolas de cuando en cuando y entrometiéndolas oportunamente en la cabida que puedan tener».
} 
«Una cuadrilla de frenéticos, con los brazos desnudos, los ojos desexcavados, llevando en las manos gruesísimas culebras que les daban varias vueltas alrededor del cuerpo y hacían grandes esfuerzos para escaparse. Apretábanlas reciamente los psilos por el pescuezo para que no mordiesen, y a pesar de sus silvos las rasgaban con los dientes y las comían vivas. Chorreaba sangre en sus bocas impuras; entre tanto otros psilos se esforzaban en arrancarles su asquerosa presa, resultando otros tantos combates sobre quién devoraría una culebra. Acompañábales atónito el populacho, gritando milagro...».

O esta carta de un viajero que asiste en Calcuta a la autoinmolación de un anciano convencido de que así salvará a su familia «de una enfermedad peligrosa»:

«Sentado el viejo a orilla de la fosa incendiada, hizo devotamente su oración levantando al cielo las manos y los ojos. Después de permanecer así media hora, le ayudaron a levantar cuatro de sus parientes más cercanos, y dieron todos cinco vueltas alrededor de la hoya, invocando a Ram y Setaram, que son dos santos suyos. Entretanto se arrancaban las mujeres el cabello, se herían el pecho y daban horrorosos gritos. Concluidas las vueltas y desprendido el anciano de su parientes, se arrojó al fuego sin dar un suspiro; y al instante todo el concurso se apresuró a echar tierra con palas hasta cubrir del todo la fosa, de suerte que puede decirse que fue a un tiempo quemado y enterrado vivo» (Diario de Madrid, 13 de febrero de 1788).

Un efecto parecido persiguen aquellos relatos, o fragmentos de ellos, que se centran en las peripecias y anécdotas del viajero, como este pasaje en el que se narra el viaje por África Central del mencionado naturalista holandés:

«Pasaron los viajeros por terrenos sumamente ásperos y difíciles, y muchas veces por bosques fragosos en que era preciso irse abriendo paso. Ya muy adelantados tierra adentro, descubrió uno de los hotentotes desde lo alto de un árbol a una tropa de elefantes, y a otro solo, algo desviado de aquellos. Acudió Mr. Vaillant a reconocerlo, tomando ciertas precauciones, y advirtió en él, al verle, menear la cabeza; pues el animal, inmóvil en la espesura y oscuridad del bosque, le parecía un gran peñasco. Disparóle, y dando la bala en medio de la frente cayó muerto. [...] Vio leones; y notó que cuando no los acosa el hambre huyen de la gente, pero encontró a uno que, más arrogante que los otros, se detuvo, y con ojos altaneros miró de pies cabeza al viajero, quien fijó igualmente la vista en él con valerosa intrepidez, sin dar indicios de huir, ni aun de separarse de su camino, y en esto se ausentó el soberbio bruto. [...] El arriesgado botanista llevaba consigo un gallo y un mico. Del primero se servía como de reloj, pudiendo fácilmente, en aquel género de vida, desarreglarse del suyo: y del segundo para que probase las frutas y las carnes antes de resolverse él a comerlas, mediante cuya precaución se libraba del riesgo de ser envenenado» (Diario de Madrid, 23 de junio de 1788).

Con razón se ha afirmado que «en el siglo de las luces se leían los viajes en la prensa periódica con la misma voracidad que los folletines en el siguiente» ${ }^{11}$. Y no cabe duda de que párrafos como éstos contribuyen al

${ }^{11}$ HELMAN, Edith. «Viajes de españoles por la España del siglo XVIII». Nueva Revista de Filología Hispánica, 1953, VII, p. 627. 
éxito del relato de viaje y a su divulgación entre el común de los lectores. Son este tipo de pasajes -escenas impactantes, lances aventureros, anécdotas curiosas-, los que hacen también decir al corresponsal del Diario de Madrid que los relatos de viaje incluidos en el Viajero Universal «van escritos con un método tan atractivo que parece cada tratado una novela según deleita», una afirmación válida para muchos de los relatos de acabamos de presentar aquí. Unos relatos que además de informar sobre los viajes más actuales y de mayor repercusión —ascensión al Montblanc, viajes en globo aerostático - tratan de instruir de forma amena mostrando lo exótico, lo diferente, la 'otredad', en una época de expansión geográfica y en la que - aunque se perciben ya los primeros indicios- todavía no ha cuajado el interés por el viaje al propio país, por los usos y las costumbres locales ${ }^{12}$. De esta forma, la prensa española de la década de los ochenta ofrece a sus lectores un género con el que compensar la —en la mayoría de los casos - imposibilidad de viajar al extranjero y con el que suplir al mismo tiempo la carencia de ficción en un siglo tan escaso en novelas.

Un repaso a la prensa de estos años no puede obviar la presencia, significativa, de relatos de viajes ficticios o imaginados. Bajo este rótulo incluyo tanto los viajes inventados por geografías reales cuanto aquellos otros realizados por lugares inexistentes, si bien presentados como reales ${ }^{13}$. Dentro de los viajes ficticios realizados por un itinerario real debemos mencionar primero las cartas marruecas de Cadalso, las cuales, antes de aparecer en forma de libro en 1793, fueron publicadas en el Correo de Madrid: el dos de febrero de 1788 ve la luz parte de la carta VII; el 30 de julio del mismo año se publica la carta XLV, y entre el 14 de febrero de 1789 y el 25 de julio de 1789 se publica la serie casi completa ${ }^{14}$. Encontramos además dos ejemplos de cartas turcas: la primera de ellas, titulada «Carta

\footnotetext{
${ }^{12}$ Para estos comienzos del viaje interior — que fue en su origen y en la mayoría de los casos un viaje en comisión oficial o de paso hacia otros países- puede consultarse el mencionado artículo de Edith Helman, así como el libro de Gaspar Gómez de la Serna. Los viajeros de la Ilustración. Madrid: Alianza Editorial, 1974, y el capítulo que Maurizio Fabbri dedica a la literatura de viajes en: AGUILAR PIÑAL, Francisco. Historia literaria de España en el siglo XVIII. Madrid: Editorial Trotta, 1996, en especial las páginas 411-414.

${ }^{13}$ Excluyo de esta forma, por cuestiones genéricas y por los límites de este artículo, los «viajes soñados» - p.ej. los que se narran en los n. ${ }^{\text {ss }} 50$ y 161 El Censor (1781-1787) o el viaje a la luna descrito en el n. ${ }^{\circ} 4$ de El Observador (1787)—, así como el Tratado sobre la Monarquía Columbina, publicado en el n. ${ }^{\circ} 30$ del Semanario erudito (1787-1781) y que tiene a palomas como protagonistas. Para estos relatos véase los estudios de Pedro Álvarez Miranda: «Sobre utopías y viajes imaginarios en el siglo XVIII español». En: Homenaje a Gonzalo torrente Ballester. Salamanca: Caja de ahorros y Monte de Piedad, 1981, pp. 351382, así como el ya citado «Los libros de viajes y las utopías en el siglo XVIII español». En: CARNERO, Guillermo (coord.). Historia de la literatura española 7. Siglo XVIII (II). Madrid: Espasa Calpe, 1995, pp. 682-707.

${ }^{14}$ Se omite el índice, la protesta literaria y las cartas LV y LXXXIII. Véase DUPUIS, Lucien y Nigel GLENDINNING (eds). Cartas marruecas. Londres: Támesis, 1966. p. XLV.
} 
de Ibrahim, en Madrid, a Fátima, en Constantinopla» fue publicada por el Diario de Madrid el 10 de diciembre de 1787; pocos días después, el 19 de diciembre, aparece la respuesta en el Correo de Madrid o de los ciegos bajo el epígrafe «Carta de Fátima en Constantinopla a Ibrahim en Madrid» ${ }^{15}$. $\mathrm{Y}$ en el diario El Censor nos topamos con tres cartas de extranjeros que relatan viajes por España: en los discursos 65 y 87 (de los años 1784 y 1786) se publican dos cartas que envía un diplomático marroquí a su amigo en Marruecos; unos años antes, en el número 22 (1781), el mismo periódico edita una «carta escrita por un inglés que ha viajado por España».

En cuanto a los relatos de viaje por geografías inexistentes, El Correo de Madrid o de los ciegos publica en sus números del 9, 12, 16 y 19 de mayo de 1787 una serie de cartas que relatan la aventura de un náufrago que recala en una región cercana al polo ártico; en el Corresponsal del Censor (1786-1788) podemos leer otro caso de naufragio, en el que el protagonista es arrastrado a una «isla cuyo nombre no es del caso decir». Pero es de nuevo el semanario El Censor el que más ejemplos ofrece: en los discursos 61, 63 y 65 (1784) nos relata el viaje a la tierra de los ayparchontes, y a lo largo de otros cinco discursos que ven la luz a lo largo de 1786 nos describe el viaje a la tierra de Cosmosia (89, 90, 101, 106 y 107).

A diferencia de los que hemos estudiado más arriba, estamos aquí ante relatos de viaje redactados por los propios periodistas o por sus colaboradores. Son relatos de viaje ficticios que cuentan con conocidos antecesores - las Cartas Persas de Montesquieu, los Viajes de Gulliver de Swift, el Robinson Crusoe de Defoe, los viajes utópicos clásicos-, pero lo característico en casi todos ellos es lo que podemos llamar la pretensión de verosimilitud con la que son transcritos en las páginas de los periódicos. Se percibe esto primero en las palabras que eligen los periodistas para presentar el viaje ante el lector. En los casos de viajes por itinerarios reales la pretensión de verosimilitud queda además patente en la elección de la nacionalidad de los viajeros; y en los casos de los viajes por geografías inexistentes en la situación geográfica del país visitado.

Por ejemplo, la carta del inglés que publica el Censor coincide con los años en los que se comienza a dar a conocer los escritos de los viajeros ingleses por España; como hemos visto en el ejemplo del viaje de Swinburn, se podían encontrar ya en la prensa reseñas o fragmentos de los relatos de estos viajeros que han terminado recibiendo el cervantino nombre de «curiosos impertinentes» ${ }^{16}$. También la elección del viajero de Marruecos, un país cuyo cuerpo diplomático desfilaba con frecuencia por las ca-

\footnotetext{
${ }^{15}$ Estas cartas, publicadas de forma anónima, han sido atribuidas por Philip Deacon a Meléndez Valdés. Véase DEACON, Philip. «Las perdidas Cartas turcas de Meléndez Valdés». Bulletin Hispanique, 1981, LXXXIII, pp. 447-462.

${ }^{16}$ Así tituló su estudio el hispanista británico Ian Robertson: Los curiosos impertinentes. Viajeros ingleses por España, 1760-1885. Madrid: Editora Nacional, 1975.
} 
lles españolas provocando la curiosidad y admiración del público, persigue una sensación de veracidad ${ }^{17}$; el mismo Censor sugiere que sus cartas marruecas han sido escritas por «alguno de los embajadores [de Marruecos] que vinieron estos años pasados de aquella Corte». La búsqueda de un efecto parecido se puede suponer en la publicación de las cartas turcas, si tenemos en cuenta que se produce en unas fechas que coinciden con un renovado interés por la nación turca y con el establecimiento de un tratado de amistad, hecho que obtuvo una fuerte resonancia en la prensa ${ }^{18}$.

También en los relatos a regiones imaginadas nos topamos con esta pretensión de verosimilitud. El corresponsal que envía a El Correo de Madrid la relación de su naufragio «más allá del estrecho de Dabis» declara ser «muy aficionado a los viajes» y afirma tajante que su viaje es «verídico suceso». Y no es casual que tanto Cosmosia como la tierra de los ayparchontes se sitúen en las regiones australes, en una época en la que las recientes hazañas de James Cook por el hemisferio sur siguen siendo tema favorito en las tertulias. Precisamente las palabras que elige el Censor para anunciar la transcripción del relato de viaje a la tierra de los ayparchontes son una buena muestra de la retórica usada por los periodistas para anclar en la realidad sus relatos de viaje imaginados:

«Entre los manuscritos que participé al público, en el año de ochenta y uno, haber adquirido de un librero de esta corte, hay uno muy particular. Es una descripción moral y política de las tierras australes incógnitas, a las cuales el autor dice haber sido arrojado por una borrasca. La simplicidad con que está escrita inclina al que la lee a tenerla por una relación verdadera. Pero el no haberse divulgado la noticia de un descubrimiento tan importante induce una vehemente sospecha de que no sea sino una ficción. Por otra parte, si es verdadera, el autor debía ignorar la astronomía o ser muy poco amante de la geografía, pues se olvidó de decirnos la longitud y latitud de los países que describe. Sea de esto lo que fuere y dejando a algún crítico laborioso el cuidado de examinar el crédito que se merece este viajero de varias naciones que dice haber reconocido durante su larga mansión en aquella parte del globo, la de que nos da una descripción más circunstanciada es la que él llama de los ayparchontes».

Aunque en ocasiones puede resultar difícil para el lector reconocer el carácter ficticio del relato ${ }^{19}$, la pretensión de verosimilitud, como bien muestra este ejemplo representativo de El Censor, no significa que los perio-

${ }^{17}$ Ya Cadalso se había inspirado en la visita, celebrada por su boato y exotismo, del embajador marroquí Ahmad al-Gazzâl al escribir sus cartas marruecas. Ver CAMARERO, Manuel. «Gazel y el embajador de Marruecos: Literatura y realidad». En: GARCÍA CASTAÑEDA, Salvador. Literatura de viajes. El viejo Mundo y el Nuevo. Madrid: Castalia, 1999, p. 133.

${ }^{18}$ Véase DEACON, Philip, op. cit, p. 447.

${ }^{19}$ La primera de las cartas marruecas que aparecen en el Correo de Madrid se publicó de forma anónima, con remite de «Cádiz, 23 de diciembre de 1786» y con la única indicación de tratarse de una carta encontrada entre los papeles heredados de un amigo. 
distas traten de confundir al lector simulando la veracidad del relato. Lo que pretenden más bien es plantearle un juego entre realidad y ficción, un juego con el que buscan ganar su confianza, invitarle a esbozar una sonrisa cómplice. Porque el relato de viaje que viene a continuación no es más que un mero vehículo para realizar una sátira de la sociedad de su tiempo.

Así, las cartas de extranjeros que viajan por España son un pretexto para proporcionar al lector un enfoque novedoso que realza el carácter anómalo de algo que tiene por natural ${ }^{20}$. En el caso de El Censor, por ejemplo, las cartas escritas por el marroquí de visita en España describen, desde una sorpresiva extrañeza, el lamentable estado de la justicia y las consecuencias nefastas de la ociosidad. El propio Censor nos explica cómo este efecto perspectivístico queda además reforzado por el país de proveniencia del viajero:

«Cuando la costumbre nos hizo familiar una cosa, no hay en ella vicio ni imperfección para ver la cual no seamos enteramente ciegos. Sólo llegamos por lo común a abrir los ojos a fuerza de desengaños. $\mathrm{Y}$ estos, una vez que se haya extendido y tomado raíces en una nación, rara vez pueden venir de dentro de ella misma. [...]. Así que conviene mucho extender en una nación cuanto es posible el juicio que otras forman de sus usos y cosas; y principalmente el de aquellas cuyas costumbres distan más de las nuestras». (Nr. 65)

Distinto, nada ingenuo, es el enfoque que se presenta en la carta escrita por el «inglés que ha viajado por España a un amigo suyo en Londres». En este caso el viajero pertenece a una nación modelo a seguir para una mayoría de ilustrados, de ahí que las conclusiones que extrae tras su recorrido por los «pueblos de España» — las causas del enflaquecimiento y despoblación del país se deben sobre todo a la manera en que están repartidas las tierras - semejan más bien un riguroso análisis hecho por un experto en economía política. El punto de vista que ofrece el viajero inglés es por tanto, más que desde fuera, desde arriba, desde una posición privilegiada para abordar el problema.

La sátira de diversos aspectos de la sociedad contemporánea también se esconde en los relatos de viajes a países imaginados. Lo habitual es que las regiones, los países, las islas descritas, sean lugares de rasgos paradisíacos o que alberguen sociedades ideales. Tal es el caso del náufrago en la «región desconocida, bajo del Polo ártico», región que describe como «símbolo del paraíso»; o el de los relatos imaginados por el Censor y el Corresponsal del Censor, en los que los viajeros nos describen la ejemplar organización de la sociedad de esas tierras incógnitas. El propósito que se

${ }^{20}$ En palabras de Baquero Goyanes, se trata de mostrar al lector «enfoques desde los que contemplar crudamente lo grotesco, deformado y envilecido de lo que en nuestra sociedad nos parece normal». Véase BAQUERO GOYANES, Mariano. Perspectivismo y contraste (De Cadalso a Pérez de Ayala). Madrid: Gredos, 1963, p.12. 
persigue aquí es mostrar de forma expresiva y plástica una contraoferta política, religiosa y moral al status quo rector en el siglo XVIII, escenificar ante el lector un ideal anhelado y oponerlo a la realidad existente.

Algo distinto, y sin duda de mayor interés por tratarse de un caso poco habitual, es el relato de viaje a la tierra de la Cosmosia. La descripción que hace el viajero francés, Mr. Ennous, de las lacras que afectan a este país imaginario es tan extrema y apocalíptica — «mismísimo infierno», «horrendo caos, donde todo es confusión, tinieblas todo»-, que no puede sino provocar un extrañamiento inicial en el lector. Sin embargo, a medida que pasa las páginas, el atento lector va hallando datos que le permiten reconocer e identificar ciertos males como propios: así por ejemplo, en el cuarto de los discursos se le revela que la situación de atraso y pobreza de cierta región de Cosmosia — que presenta curiosas semejanzas con España- se debe a la persistencia en la cima de la pirámide estamental de una aristocracia hereditaria y ociosa. De esta forma, la distopía, la antiutopía radical de Cosmosia, se va transformando ante los ojos del lector en una alegoría satírica de la España contemporánea.

Todos estos ejemplos patentizan de qué manera se sirven los periodistas ilustrados de un género de tanto éxito en aquellos años, el relato de viaje, para encauzar a través de él, de forma oblicua y velada, una crítica a las estructuras de la sociedad y a los órganos de poder. El carácter indirecto y el enmascaramiento de la crítica están en parte motivados por la existencia de la censura, pero también por el afán de aumentar el poder persuasivo, al obligar al lector a descubrir él mismo los objetivos y la intencionalidad de la crítica. En este sentido podemos hablar aquí de una instrumentalización satírica del relato de viaje. Si antes hemos visto ejemplos de relatos de viaje al servicio del prodesse et delectare y en el marco de la Ilustración en cuanto movimiento cultural que trata de divulgar una actitud mental más abierta y cosmopolita, ahora, particularmente en el caso de El Censor, estamos ante relatos instrumentalizados al servicio de la Ilustración en cuanto corriente ideológica que cuestiona el ordenamiento político y social. En ambos casos podemos hablar de relato de viaje ilustrado, un género que, tanto en su variante real como en la ficticia, vivió su apogeo en la prensa de la década de los ochenta, corto periodo de esplendor truncado por la Real Orden del 24 de febrero de 1791.

\section{REFERENCIAS BIBLIOGRÁFICAS}

ÁLVAREZ MIRANDA, Pedro. «Los libros de viajes y las utopías en el siglo XVIII español». En: CARNERO, Guillermo (coord.). Historia de la literatura española 7. Siglo XVIII (II). Madrid: Espasa Calpe, 1995, pp. 682-707.

—. «Sobre utopías y viajes imaginarios en el siglo XVIII español». En: Homenaje a Gonzalo torrente Ballester. Salamanca: Caja de Ahorros y Monte de Piedad, 1981, pp. 351-382. 
BAQUERO GOYANES, Mariano. Perspectivismo y contraste (De Cadalso a Pérez de Ayala). Madrid: Gredos, 1963,

CAMARERO, Manuel. «Gazel y el embajador de Marruecos: Literatura y realidad». En: GARCÍA CASTAÑEDA, SALVADOR (ed.). Literatura de viajes. El viejo Mundo y el Nuevo. Madrid: Castalia, 1999, pp. 133-141.

DEACON, Philip. «Las perdidas Cartas turcas de Meléndez Valdés». Bulletin Hispanique, LXXXIII, 1981, pp. 447-462.

CADALSO, José de. Cartas marruecas. DUPUIS, Lucien y Nigel GLENDINNING (eds.). Londres: Támesis, 1966.

FABBRI, MAURIZIO. «Literatura de viajes». En: AGUILAR PIÑAL, Francisco (ed.). Historia literaria de España en el siglo XVIII. Madrid: Trotta, 1996, pp. 407-423.

FERRONE, Vicenzo y y Daniel ROCHE (eds.). Diccionario histórico de la Ilustración. Madrid: Alianza Editorial, 1998,

GÓMEZ DE LA SERNA, Gaspar. Los viajeros de la Ilustración. Madrid: Alianza Editorial, 1974.

HELMAN, Edith. «Viajes de españoles por la España del siglo XVIII». Nueva Revista de Filología Hispánica, VII, 1953, pp. 618-629.

ROBERTSON Ian: Los curiosos impertinentes. Viajeros ingleses por España, 1760-1885. Madrid: Editora Nacional, 1975.

TORRES SANTO DOMINGO, Marta. «Los viajes del capitán Cook en el siglo XVIII. Una revisión bibliográfica». En: Biblio $3 W$, Revista bibliográfica de geografía y ciencias sociales, VIII, núm. 441, 2003.

URZAINQUI, Inmaculada. «Un nuevo instrumento cultural: la prensa periódica». En: ÁLVAREZ BARRIENTOS, Joaquín; François, LOPEZ e Inmaculada URZAINQUI. La república de las letras en la España del siglo XVIII. Madrid:, CSIC, 1995, pp. 125 216.

Fecha de recepción: 4 de marzo de 2010

Fecha de aceptación: 8 de septiembre de 2011 
